\title{
The ASM Materials Education Foundation Materials Camp® Program - Introducing High School Teachers and Students to Materials Science
}

\author{
J.J. Frafjord* and C.R. Hayes** \\ * IMR KHA- Portland, 5687-A S.E. International Way, Portland, OR 97222 \\ ** ASM Materials Education Foundation, 9639 Kinsman Rd., Materials Park, OH 44073
}

The ASM-Materials Education Foundation was founded in 1953, and its mission is "To excite young people in Materials, Science, and Engineering careers." The ASM Materials Education Foundation has been active in efforts to increase the number of people entering the materials science and related fields.

The ASM-MEF Materials Camp® programs are built on the concept that every-day materials represent the perfect context to enhance students' interest in further science studies. The effectiveness of this concept has been confirmed by the positive impact on both students and teachers. Since 2000, over 3,000 high school teachers, and separately over 6,200 high school students have participated in a "Materials Camp", which typically is 5 days/ 40 hours of lab-based involvement in materials. Shorter 1 or 2 day camps are also available.

The Materials Camps for teachers is often a multitude of simple materials science experiments that can be conducted in the classroom with a minimal amount of effort or fancy equipment. The Materials Camps for students can either follow a similar format of simple and fun experiments, or the camp can lead the students through a failure analysis project of a broken part.

Both optical microscopy and electron microscopy are significant tools in learning about materials and in conducting a failure analysis. Microscopes used in the camps are generally borrowed through universities, companies, or vendors, while people familiar with the equipment often volunteer to help during the camp.

The history, impact, metrics, and educational philosophy of the Materials Camp will be discussed through examples from both the chapter and national levels.

Reference:

A. Asphahani, R. Decker, C. Hayes, R. Parrington, and L. Schwartz, "The ASM Materials Camp® Initiative: Getting Young People Interested in Science and Excited about Engineering Careers," Advanced Materials \& Processes, Volume 168, Issue 10 (October 2010). 


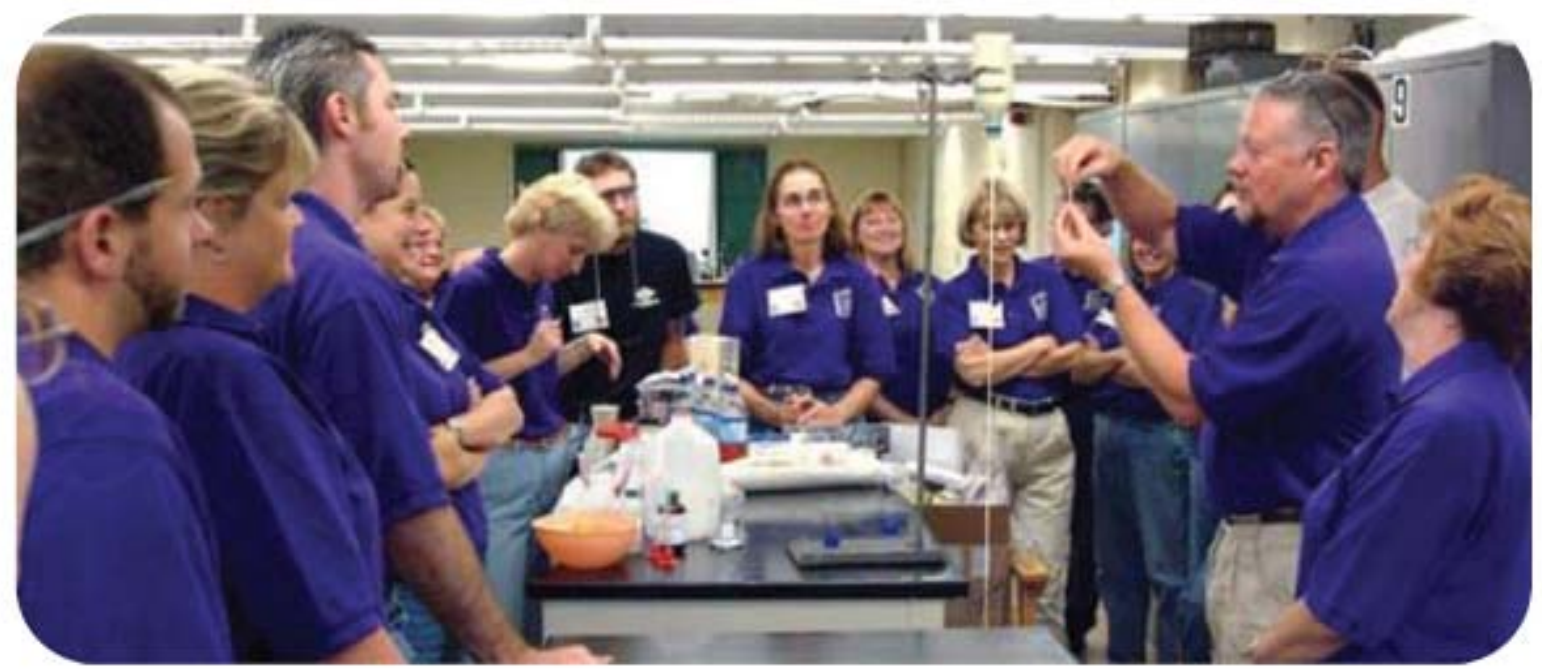

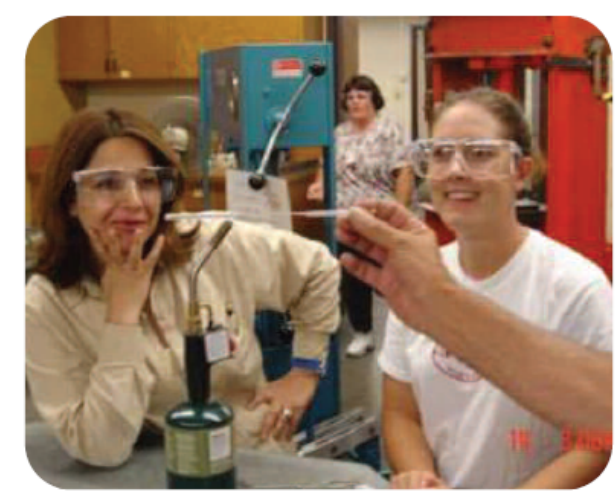
credit hours toward master's degrees are teaching materials science-type

$87 \%$ of participating teachers are using the camp in their classrooms, and $42 \%$ are using 4 or more lab demos

$84 \%$

of ASM Materials Camp ${ }^{\circledR}$ students entered science fields $66 \%$ enrolled in engineering $41 \%$ majored in materials science

An estimated 4,517 students graduating in science \& engineering

Data based on 2009 survey results
564 teachers acquired Over 130 teachers courses in their high schools at least one tool acquired during in their classrooms
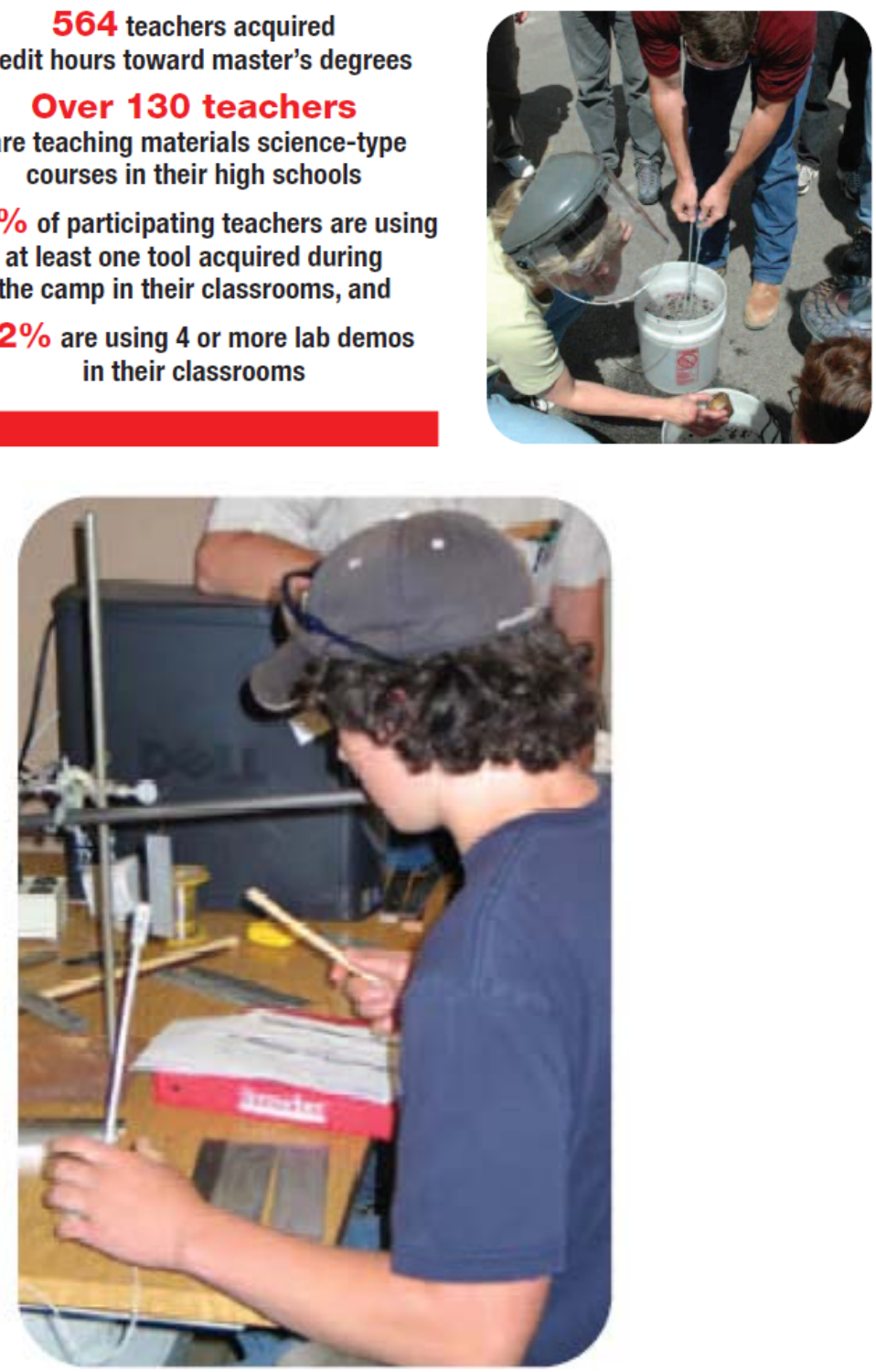